\title{
Effects of Substance Misuse and Family History of Substance Use Disorder on Delay Discounting in Adolescents and Young Adults with Attention- Deficit/Hyperactivity Disorder
}

\author{
Maria Paraskevopoulou ${ }^{a, b}$ Daan van Rooij ${ }^{b}$ Aart H. Schene ${ }^{a, b}$ \\ Anouk P.J. Scheres $^{c}$ Jan K. Buitelaar ${ }^{b, d}$ Arnt F. A. Schellekens ${ }^{a, e}$ \\ aDepartment of Psychiatry, Donders Institute for Brain, Cognition and Behaviour, Radboud University Medical \\ Center, Nijmegen, The Netherlands; 'bepartment of Cognitive Neuroscience, Donders Institute for Brain, Cognition, \\ and Behaviour, Radboud University Medical Centre, Nijmegen, The Netherlands; 'Behavioural Science Institute, \\ Radboud University, Nijmegen, The Netherlands; ${ }^{\mathrm{K} K a r a k t e r}$ Child and Adolescent Psychiatry, Nijmegen, The

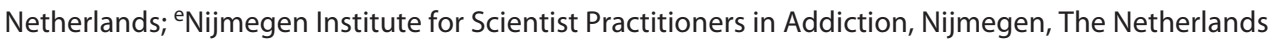

\section{Keywords}

Substance use disorder - Substance misuse · Attentiondeficit/hyperactivity disorder - Callous-unemotional traits . Delay discounting

\footnotetext{
Abstract

Background: Attention-deficit/hyperactivity disorder (ADHD) and substance use disorder (SUD) often co-occur. Both disorders are characterized by impulsive choice. However, little is known about the effects of substance misuse (SM) and family history of SUD (FH) on impulsive choice in ADHD-SUD comorbidity. Impulsive choice is also linked to callous-unemotional (CU) traits, which are suggested to play a role in ADHD-SUD comorbidity. Our aim was to examine the effects of (1) FH and (2) SM on impulsive choice, while exploring the role of $\mathrm{CU}$ traits. Methods: Impulsive choice was assessed with the delay discounting (DD) task. We compared task performance across (1) ADHD patients and controls with or without FH of SUD (ADHD FH+: $n=86$; ADHD
}

$\mathrm{FH}-: n=63$; control $\mathrm{FH}+: n=49$; control FH-: $n=72$; mean age of the whole sample [ $n=270]: 16.39$, SD: 3.43 ) and (2) family history-matched ADHD groups with and without SM and controls (ADHD + SM: $n=62$; ADHD-only: $n=62$; controls: $n=62$; mean age of the whole sample [ $n=186]$ : 18.01, SD: 2.71). Effects of $C U$ traits were explored by adding this as a covariate in all analyses. Results: (1) There was no main effect of FH on DD. (2) We found increased DD in ADHD + SM compared to ADHD-only and no difference between ADHDonly and controls. Finally, increased DD was associated with increased callous traits only in ADHD FH+ and control FH+ Conclusions: In adolescents and young adults with ADHD, high impulsive choice might only be present in those with comorbid $\mathrm{SM}$ and in an $\mathrm{FH}+$ subgroup with high callous traits. This suggests that impulsive choice in ADHD might result from (1) effects of SM and (2) a combined effect of SUD vulnerability and high callousness. Future studies should investigate efficacy of early interventions, targeting $\mathrm{CU}$ traits.

(c) 2020 The Author(s)

Published by S. Karger AG, Basel karger@karger.com www.karger.com/ear Karger"
(C) 2020 The Author(s) Published by S. Karger AG, Basel

Karger Open access This article is licensed under the Creative Commons AttributionNonCommercial-NoDerivatives 4.0 International License (CC BYNC-ND) (http://www.karger.com/Services/OpenAccessLicense) Usage and distribution for commercial purposes as well as any distribution of modified material requires written permission.
Maria Paraskevopoulou

Departments of Psychiatry \& Cognitive Neuroscience, Radboud University Medical Center \& Donders Institute for Brain, Cognition and Behaviour

Kapittelweg 29, NL-6525 Nijmegen (The Netherlands)

Maria.Paraskevopoulou@ radboudumc.nl 


\section{Introduction}

Attention-deficit/hyperactivity disorder (ADHD) is a childhood-onset neurodevelopmental disorder with a prevalence of about 7\% [1], which persists into adulthood for a substantial portion of patients [2]. Adolescent and adult patients with ADHD have a higher risk for substance use disorder (SUD), with prevalence rates up to $58 \%[3,4]$, contrasted with rates of $4-5 \%$ [5] in the general population. Moreover, ADHD patients with comorbid SUD demonstrate early substance use onset, fast transition from recreational substance use to dependence, and poor ADHD and SUD treatment responses, compared to ADHD-only and SUD-only patients, respectively [6-8]. Insight into the mechanisms contributing to the frequent co-occurrence of these conditions is needed to facilitate the development of (more) effective prevention and treatment interventions for ADHD-SUD patients.

Patients with ADHD and SUD show various (endo) phenotypic similarities. For instance, impulsive choice seems to play a central role in both disorders [9-13]. Preference for smaller-immediate over larger-delayed rewards reflects one aspect of impulsive choice [10]. This is usually assessed with tasks of delay discounting (DD), which measure the interpersonal difference in the decrease of a reward's subjective value (SV) as the delay to that reward increases [10]. A steeper discounting of delayed rewards is typically interpreted as a reflection of impulsive choice. Importantly, literature provides evidence for the heritability of DD [14], indicating this as a potentially shared endophenotype based on shared genetic liability between the two disorders.

In $\mathrm{ADHD}$, meta-analyses found steeper discounting of rewards with a medium effect size for patients compared to controls $[9,10]$. Patients with SUD and problematic substance use also showed steeper DD compared to controls [11].

Rodent studies demonstrate more impulsive choices as a consequence of chronic drug administration [15], suggesting that steeper discounting in addicted humans may also be a consequence of (excessive) substance use. Of note, studies in the general population also show steeper DD for those with a positive family history of SUD $(\mathrm{FH}+)$ compared to those with a negative family history (FH-) $[16,17]$. This suggests preexisting effects of family history of SUD (FH) on DD, which might increase the vulnerability to substance-seeking behaviors.

Impulsive choice in patients with ADHD might on the one hand be related to ADHD symptoms, but on the other hand also to substance use, either (1) in a subset of
ADHD patients with $\mathrm{FH}+$ or (2) in a subset of adolescent and adult patients with ADHD and substance misuse (SM). Indeed, a study on adult ADHD patients showed greater discounting only in those with comorbid cocaine dependence, but similar performance between a purely ADHD group and controls [18]. As a result, the extent to which impulsive choice in ADHD studies with adolescents and adults reflects a premorbid familial vulnerability for SUD or a consequence of SM is still unclear.

Interestingly, the majority of the genetic liability shared between ADHD and alcohol use disorder was found to be also shared with conduct disorder (CD) [19]. The callous-unemotional component of psychopathy, also known as callous-unemotional (CU) traits [20], is suggested to be a modifier to CD diagnosis [21]. Moreover, Acheson et al. [22] found that greater discounting in their (non-ADHD) FH+ group was mediated by this group's greater number of individuals with high antisocial psychopathic traits. Similarly, substance abusers with comorbid antisocial personality disorder (ASP) were found to discount rewards at higher rates than substance abusers without antisocial personality disorder [23]. Effects of psychopathic features (e.g., CU traits) and variability of their prevalence across studies might have further contributed to mixed results in the literature.

The aim of this study is three-fold. First, we aim to examine the effects of FH on DD, comparing behavioral data of adolescent and young adult ADHD patients and controls with $\mathrm{FH}+$ and $\mathrm{FH}-$. We hypothesize steeper DD in $\mathrm{FH}+$ individuals, independent of ADHD diagnosis. Second, we aim to investigate the effects resulting from $\mathrm{SM}$ on $\mathrm{DD}$, comparing performance across ADHD patients with and without SM and controls (without SM), matched for FH of SUD. Based on ADHD and SUD literature, we hypothesize greater DD in ADHD patients with and without SM compared to controls and even greater discounting in ADHD patients with SM compared to those without SM. Finally, we explored the association between DD and CU traits in all analyses.

\section{Materials and Methods}

\section{Participants}

Our sample was part of the NeuroIMAGE cohort [24]. This is the Dutch follow-up of the International Multicenter ADHD Genetics (IMAGE) study, which recruited ADHD and control families, examining cognitive, neural, and genetic correlates of ADHD. Data on substance use were also collected. The project and recruitment procedure are described in online suppl. material 1; see www. karger.com/doi/10.1159/000509147 for all online suppl. material and the NeuroIMAGE design paper [24]. Briefly, NeuroIMAGE 
Table 1. Effects of FH: sample characteristics

\begin{tabular}{|c|c|c|c|c|c|}
\hline & $\begin{array}{l}\text { ADHD FH- } \\
(n=63)\end{array}$ & $\begin{array}{l}\text { ADHD FH+ } \\
(n=86)\end{array}$ & $\begin{array}{l}\text { Control FH- } \\
(n=72)\end{array}$ & $\begin{array}{l}\text { Control FH+ } \\
(n=49)\end{array}$ & $p$ value $^{\mathrm{a}}$ \\
\hline Age $($ mean $\pm S D)$ & $16.55 \pm 3.36$ & $16.36 \pm 3.36$ & $16.45 \pm 3.98$ & $16.14 \pm 2.79$ & 0.938 \\
\hline $\mathrm{IQ}^{\mathrm{f}}($ mean $\pm \mathrm{SD})$ & $103.69 \pm 15.1$ & $97.65 \pm 14.48$ & $108.09 \pm 13.53$ & $108.29 \pm 14.85$ & $<0.001^{\mathrm{b}, \mathrm{c}, \mathrm{g}}$ \\
\hline Site (Nijmegen/Amsterdam) & $41 / 22$ & $49 / 37$ & $31 / 41$ & $28 / 21$ & 0.073 \\
\hline $\mathrm{DBD}($ yes/no) & $15 / 48$ & $18 / 68$ & $0 / 72$ & $0 / 49$ & $<0.001^{\mathrm{b}-\mathrm{e}}$ \\
\hline \multicolumn{6}{|l|}{ Conners' parents DSM-IV } \\
\hline Inattention $(\mathrm{M} \pm \mathrm{SD})$ & $64.02 \pm 11.33$ & $64.39 \pm 11.79$ & $45.93 \pm 5.29$ & $47.89 \pm 5.68$ & $<0.001^{\mathrm{b}-\mathrm{e}}$ \\
\hline Hyperactivity-impulsivity (mean \pm SD) & $66.55 \pm 15.11$ & $69.09 \pm 14.19$ & $46.19 \pm 4.95$ & $46.63 \pm 5.74$ & $<0.001^{\mathrm{b}-\mathrm{e}}$ \\
\hline Total $(\mathrm{M} \pm \mathrm{SD})$ & $67.08 \pm 13.31$ & $68.17 \pm 13.21$ & $45.44 \pm 4.99$ & $46.98 \pm 5.53$ & $<0.001^{\mathrm{b}-\mathrm{e}}$ \\
\hline \multicolumn{6}{|l|}{ Conners' teacher/self DSM-IV } \\
\hline Inattention $(\mathrm{M} \pm \mathrm{SD})$ & $64.31 \pm 11.68$ & $63.43 \pm 12.09$ & $47.88 \pm 9.99$ & $47.91 \pm 7.49$ & $<0.001^{\mathrm{b}-\mathrm{e}}$ \\
\hline Hyperactivity-impulsivity $($ mean $\pm \mathrm{SD})$ & $4.9 \pm 2.65$ & $5.19 \pm 2.58$ & - & - & 0.05 \\
\hline \multicolumn{6}{|l|}{ CU traits } \\
\hline Uncaring $($ mean $\pm \mathrm{SD})$ & $9.68 \pm 3.89$ & $9.17 \pm 3.71$ & $6.21 \pm 2.92$ & $6.55 \pm 3.25$ & $<0.001^{\mathrm{b}-\mathrm{e}}$ \\
\hline Callousness (mean \pm SD) & $7.38 \pm 3.25$ & $6.38 \pm 3.04$ & $5.31 \pm 2.46$ & $5.22 \pm 2.58$ & $<0.001^{\mathrm{d}, \mathrm{e}}$ \\
\hline Unemotional (mean \pm SD) & $7.43 \pm 3.21$ & $7.01 \pm 3.44$ & $6.36 \pm 2.76$ & $6.43 \pm 2.39$ & 0.153 \\
\hline Total score & $26.51 \pm 8.24$ & $24.28 \pm 7.67$ & $19.46 \pm 5.89$ & $19.59 \pm 6.09$ & $<0.001^{\mathrm{b}-\mathrm{e}}$ \\
\hline
\end{tabular}

FH, family history of SUD; SUD, substance use disorder; ADHD, attention-deficit/hyperactivity disorder; ADHD FH-, ADHD with negative family history; ADHD FH+, ADHD with positive family history; Control FH-, controls with negative family history; Control $\mathrm{FH}+$, controls with positive family history; DBD, disruptive behavioral disorder (i.e., presence of oppositional defiant disorder or conduct disorder); CU traits, callous-unemotional traits. ${ }^{\text {a }}$ Group differences were examined with one-way ANOVAs for age and IQ and with $\chi^{2}$ tests for gender, site, DBD and ADHD medication. ${ }^{b}$ Post hoc comparisons (corrected with the Bonferroni-Holm method) showed a difference between ADHD FH+ and Control FH-. ${ }^{c}$ Post hoc comparisons (corrected with the Bonferroni-Holm method) showed a difference between ADHD FH+ and Control FH+. ${ }^{\mathrm{d}}$ Post hoc comparisons (corrected with the Bonferroni-Holm method) showed a difference between ADHD FH- and Control FH-. ${ }^{\text {e }}$ Post hoc comparisons (corrected with the Bonferroni-Holm method) showed a difference between ADHD FH- and Control FH+. ${ }^{\mathrm{f}}$ IQ level was estimated based on the cognitive performance in Block Design \& Vocabulary tasks of Wechsler Intelligence Scale for Children (WISC) and Wechsler Adult Intelligence Scale (WAIS). ${ }^{\mathrm{g}}$ Post hoc comparisons (corrected with the Bonferroni-Holm method) showed a difference between ADHD FH+ and ADHD FH-.

consisted of 412 ADHD patients (mean age 16.6, SD 3.4; 68\% males) and 262 controls (mean age 16.6, SD 3.7; 49\% males). DD data were available for 370 ADHD patients and 226 controls. Exclusion criteria applied in this sample included (1) having IQ $<70$ ( $n=20)$, (2) not having stopped ADHD medication $48 \mathrm{~h}$ before testing or consumption of alcohol or use of drugs $24 \mathrm{~h}$ before testing $(n=17),(3)$ missing data on parental use $(N=175)$, or (4) on self-substance use $(n=48)$, or $(5)$ on CU traits $(n=4)$. After all the exclusion criteria were applied, 2 subpopulations were identified for the 2 main research questions:

1. Subpopulation for effects of FH of SUD

For examining the effects of FH of SUD on DD, the sample consisted of an ADHD FH- group $(n=63)$, an ADHD FH+ group $(n=86)$, a control $\mathrm{FH}$ - group $(n=72)$, and a control $\mathrm{FH}+$ group ( $n=49$; mean age of the whole sample $[n=270]: 16.39$, SD: 3.43 ). Age distribution can be found in online suppl. Figure 1. This sample consisted of participants without SM to avoid confounding ef-

Substance Use Trait-State Effects on

Delay Discounting in ADHD fects resulting from this. Sample characteristics are summarized in Table 1.

2. Sub-population for effects of SM

For investigating the effects resulting from SM, the study sample consisted of an ADHD group without SM (ADHD-only; $n=$ 62 ), an ADHD group with SM (ADHD + SM; $n=62$ ), and a control group without SM ( $n=62$; mean age of the whole sample [ $n=186]$ : 18.01, SD: 2.71). Age distribution can be found in online suppl. Figure 2. All participants, including ADHD + SM patients, stopped using substances at least $24 \mathrm{~h}$ before testing. Table 2 summarizes sample characteristics.

\section{Instruments/Measurements}

Attention-deficit/hyperactivity disorder

The ADHD diagnostic algorithm included assessment with the Schedule for Affective Disorders and Schizophrenia for SchoolAge Children-Present and Lifetime Version (K-SADS) [25] and 
Table 2. Effects of SM: sample characteristics

\begin{tabular}{|c|c|c|c|c|}
\hline & $\begin{array}{l}\text { ADHD-only } \\
(n=62)\end{array}$ & $\begin{array}{l}\text { ADHD + SM } \\
(n=62)\end{array}$ & $\begin{array}{l}\text { Control } \\
(n=62)\end{array}$ & $p$ value $^{\mathrm{a}}$ \\
\hline FH of SUD (FH-/FH+) & $16 / 46$ & $16 / 46$ & $16 / 46$ & 1.00 \\
\hline Gender (male/female) & $54 / 8$ & $54 / 8$ & $22 / 40$ & $<0.001^{\mathrm{b}, \mathrm{c}}$ \\
\hline $\mathrm{IQ}^{\mathrm{d}}($ mean $\pm \mathrm{SD})$ & $99.92 \pm 15.76$ & $93.95 \pm 15.12$ & $107.39 \pm 14.32$ & $<0.001^{\mathrm{b}, \mathrm{c}, \mathrm{e}}$ \\
\hline Site (Nijmegen/Amsterdam) & $41 / 21$ & $32 / 30$ & $30 / 32$ & 0.106 \\
\hline ADHD medication (yes/no) & $38 / 24$ & $26 / 36$ & $0 / 62$ & $<0.001^{\mathrm{b}, \mathrm{c}}$ \\
\hline \multicolumn{5}{|l|}{ Conners' parents DSM-IV } \\
\hline Inattention $($ mean $\pm \mathrm{SD})$ & $62.17 \pm 10.89$ & $64.25 \pm 10.53$ & $47.02 \pm 5.38$ & $<0.001^{\mathrm{b}, \mathrm{c}}$ \\
\hline Hyperactivity-impulsivity (mean \pm SD) & $68.54 \pm 14.59$ & $68.03 \pm 13.82$ & $46.29 \pm 5.31$ & $<0.001^{\mathrm{b}, \mathrm{c}}$ \\
\hline Total $($ mean $\pm S D)$ & $66.67 \pm 13.67$ & $68.19 \pm 12.69$ & $46.21 \pm 5.28$ & $<0.001^{\mathrm{b}, \mathrm{c}}$ \\
\hline \multicolumn{5}{|l|}{ Conners' teacher/self DSM-IV } \\
\hline Inattention $($ mean $\pm \mathrm{SD})$ & $6.18 \pm 2.1$ & $6.3 \pm 1.87$ & - & 0.68 \\
\hline Hyperactivity-impulsivity (mean \pm SD) & $5.06 \pm 2.51$ & $4.68 \pm 2.16$ & - & 0.359 \\
\hline \multicolumn{5}{|l|}{ CU traits } \\
\hline Uncaring (mean \pm SD) & $9.18 \pm 3.17$ & $11.32 \pm 3.67$ & $6.42 \pm 3.04$ & $<0.001^{\mathrm{b}, \mathrm{c}, \mathrm{e}}$ \\
\hline Callousness (mean \pm SD) & $6.47 \pm 3.06$ & $7.55 \pm 3.57$ & $5.26 \pm 2.59$ & $<0.001^{\mathrm{b}}$ \\
\hline Unemotional(mean \pm SD) & $7.06 \pm 3.54$ & $7.81 \pm 2.91$ & $6.32 \pm 2.49$ & $0.025^{\mathrm{b}}$ \\
\hline Total score & $24.53 \pm 7.77$ & $29.02 \pm 7.99$ & $19.37 \pm 5.95$ & $<0.001^{b, c, e}$ \\
\hline \multicolumn{5}{|c|}{ 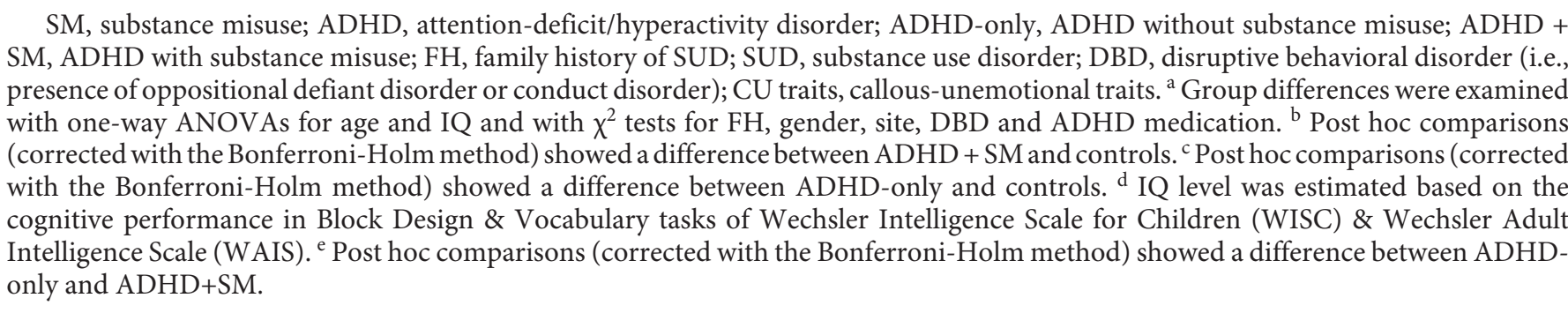 } \\
\hline
\end{tabular}

the Conners' ADHD questionnaires completed by parents, teachers, and participants [26, 27]. The diagnostic algorithm is described in detail in online suppl. material 1 and the main design paper of NeuroIMAGE [24].

\section{Substance Use}

1. FH of SUD

Parental substance use was assessed with the Alcohol Use Disorders Identification Test (AUDIT) [28], the Drug Abuse Screening Test (DAST) [29], and the Fagerström Test for Nicotine Dependence (FTND) [30] via phone. Self-Administered Timeline Follow Back (TLFB) for alcohol consumption and nicotine use in the past 30 days was also used [31, 32]. Alcohol use disorder was defined for a score of 9 or higher on the AUDIT [33] or on average 14 or more drinks per week in the past 30 days on the TLFB for males [34], and for females, a score of 8 or higher on the AUDIT [33] or on average 7 or more drinks per week in the past 30 days on the TLFB [34]. Drug use disorder was identified for a score of
6 or higher on the DAST [29], while nicotine use disorder was indicated for a score of 5 or higher on the FTND [30,35] or on average 10 or more cigarettes per day in the past 30 days on the TLFB [32].

Alcohol, drug, or nicotine use disorder in at least one of the parents indicated $\mathrm{FH}+$. Absence of alcohol, drug, and nicotine use disorder in both parents marked FH-. Missing data for at least 1 parent led to participant exclusion $(n=175)$ unless the data of the other parent indicated SUD and were thus sufficient to mark FH+. 2. Substance Misuse

Substance use in participants was assessed with the Dutch version of the Self-Reported Delinquency Scale (SRD) [36, 37]. Daily alcohol or nicotine use or at least weekly drug use was classified as SM [38]. Less frequent use indicated no substance misuse. Participants were excluded for missing data in at least one of the scales of the questionnaire (i.e., alcohol, drug, or nicotine; $n=48$ ).

Groups for effects of SM (i.e., ADHD-only, ADHD + SM, and controls) were matched perfectly with FH of SUD to avoid inter- 
Table 3. Group differences in delay discounting (AUC)

\begin{tabular}{|c|c|c|c|c|c|}
\hline \multicolumn{6}{|c|}{ Effects of FH of SUD } \\
\hline $\mathrm{AUC}($ mean $\pm \mathrm{SD})$ & $\begin{array}{l}\text { ADHD FH- } \\
(n=63)\end{array}$ & $\begin{array}{l}\text { ADHD FH+ } \\
(n=86)\end{array}$ & $\begin{array}{l}\text { Control FH- } \\
(n=72)\end{array}$ & $\begin{array}{l}\text { Control FH+ } \\
(n=49)\end{array}$ & $p\left(\eta p^{2}\right)$ \\
\hline & $0.408 \pm 0.236$ & $0.371 \pm 0.231$ & $0.420 \pm 0.228$ & $0.369 \pm 0.209$ & $0.164^{\mathrm{a}}(0.008), 0.57^{\mathrm{b}}(0.001), 0.073^{\mathrm{c}}(0.013)$ \\
\hline \multicolumn{6}{|l|}{ Effects of SM } \\
\hline \multirow[t]{2}{*}{$\mathrm{AUC}($ mean $\pm \mathrm{SD})$} & $\begin{array}{l}\text { ADHD-only } \\
(n=62)\end{array}$ & $\begin{array}{l}\mathrm{ADHD}+\mathrm{SM} \\
(n=62)\end{array}$ & $\begin{array}{l}\text { Control } \\
(n=62)\end{array}$ & $p\left(\eta p^{2}\right)$ & \\
\hline & $0.386 \pm 0.221$ & $0.302 \pm 217$ & $0.369 \pm 0.206$ & $0.045(0.034)$ & \\
\hline
\end{tabular}

$p$ values from the final models as indicated by the stepwise analysis. AUC, area under the curve; FH, family history of SUD; SUD, substance use disorder; ADHD, attention-deficit/hyperactivity disorder; ADHD FH-, ADHD with negative family history; ADHD FH+, ADHD with positive family history; Control $\mathrm{FH}-$, controls with negative family history; Control FH+, controls with positive family history; ADHD-only, ADHD without substance misuse; ADHD+SM, ADHD with substance misuse. ${ }^{\mathrm{a}} p$ value for $\mathrm{ADHD}$ effect. ${ }^{\mathrm{b}} p$ value for family history effect. ${ }^{c} p$ value for ADHD $\times \mathrm{FH}$ interaction effect; AUCs are before transformation to normality.

ference of potential preexisting effects of $\mathrm{FH}$. These groups were also matched optimally with age, and only ADHD-only and $\mathrm{ADHD}+\mathrm{SM}$ were matched perfectly with gender to prevent interference of other potential confounding variables. Matching was conducted with MatchIt in $\mathrm{R}$ ( $\mathrm{R}$ version 3.6.2; Rstudio version 1.2.5033) [39, 40].

\section{CU Traits}

CU traits were assessed with the self-report Inventory of Callous-Unemotional Traits (ICU) [41], which consisted of 3 subscales: uncaring, callousness, and unemotional. ICU has an internal consistency of Cronbach's $\alpha=0.74-0.85$ [41, 42].

\section{DD Task}

During this experimental task [43], participants were asked to choose between a small-immediate and a large-delayed reward. Small-immediate rewards varied between 1 and 4 cents and were delivered after $0 \mathrm{~s}$. Large-delayed rewards were of 5 cents and were delivered after a variable delay of $5,10,20,30$, or $60 \mathrm{~s}$. The smallimmediate reward was paired twice with the large-delayed reward for every delay. In each trial, small-immediate and large-delayed rewards were represented by 2 airplanes on the right and left of the screen. These carried the corresponding amount of money, which was indicated by a number and the appropriate number of coins below the airplane. The height the airplanes were flying at indicated the delay of the large reward (i.e., the longer the delay, the greater the height). The right or left position of the airplane for the large-delayed reward was balanced across trials. Participants were required to press the button corresponding to the airplane of their choice (right or left). The chosen airplane then dropped the carried amount of money into participants' money basket on the bottom of the screen, immediately for the small reward or after the appropriate delay for the large-delayed reward. That was followed by 2 feedback screens. During these, participants were informed about the current and the total amount of money won. Participants received the total amount of money won after completion of the task.
The task included a practice block of 10 trials and a test block of 40 trials. Participants were informed of the number of trials before they started in order to ensure that they realized that choosing the immediate reward would result in a shorter task duration.

\section{Analyses}

Preprocessing

SVs reflected the value of the small-immediate reward in each delay for which a participant showed indifference to the large-delayed reward [44]. These were calculated based on the proportion of delayed choices [45]. SVs and delays were then normalized (i.e., SVs as proportions of the large-delayed reward and delays as proportions of the maximum delay) and were used to compute the area under the curve (AUC) [43]. This ranged between 0 and 1 . Smaller AUC indicated steeper discounting and thus higher impulsive choice. Preprocessing is described in detail in online suppl. material 1 . The $\log _{10}$ transformation was applied to normalize AUC. Homogeneity of variances and homogeneity of regression slopes were also checked (Table 3).

Main Analyses

1. Effects of FH of SUD

Differences in AUC were examined with a two-way ANCOVA with ADHD (2 levels: ADHD and controls), FH (2 levels: FH- and $\mathrm{FH}+$ ), and the $\mathrm{ADHD} \times \mathrm{FH}$ interaction as independent variables. Age, gender, and site were included in the models as covariates.

2. Effects of SM

We performed a one-way ANCOVA with group (3 levels: AD$\mathrm{HD}$-only, ADHD + SM, and controls) as the independent variable and age, gender, and site as covariates.

\section{Exploratory Analysis with CU Traits}

To explore the effects of CU traits, scores from the uncaring, callousness, and unemotional ICU scales were added as covariates to the models for (1) effects of FH and (2) effects of SM. We then applied stepwise regression analysis (forward and backward meth- 
Fig. 1. Subjective values for each delay during delay discounting (DD) task. FH-, negative family history of SUD (black dashed line); FH+, positive family history of SUD (blue solid line); error bars, standard error of the mean.

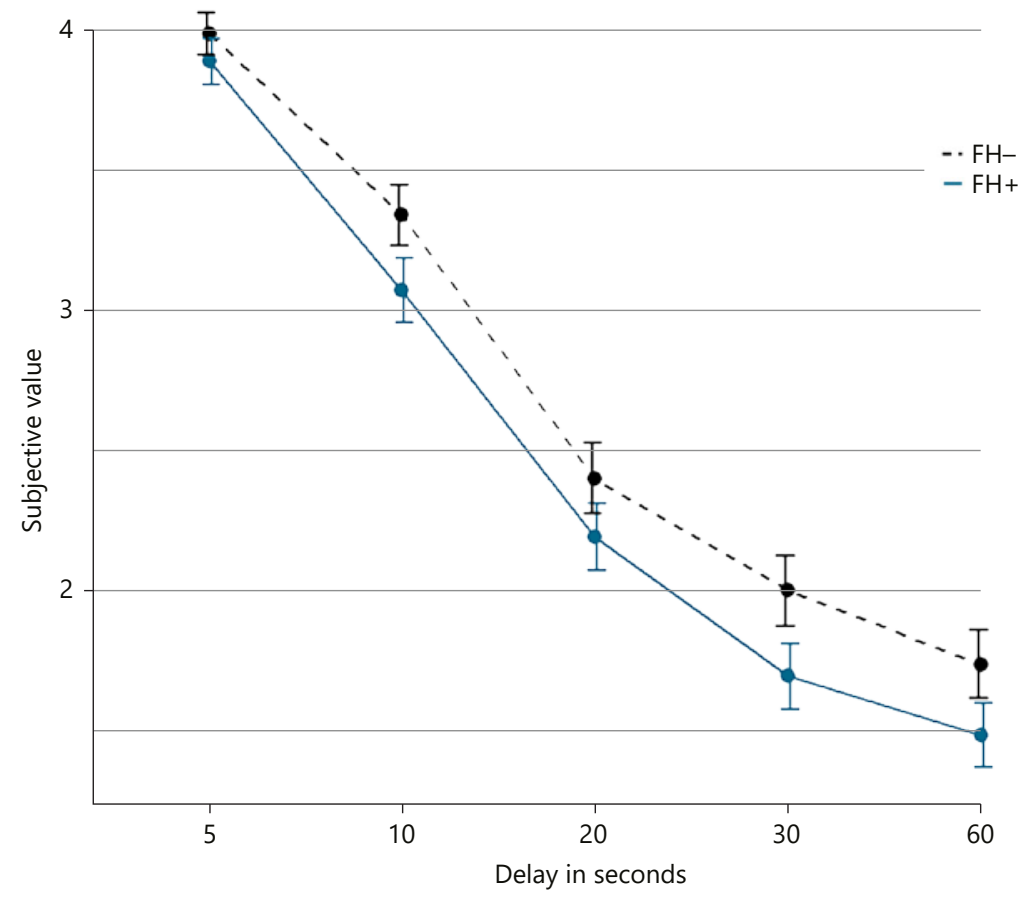

Exploratory Analysis with CU Traits

1. Effects of FH of SUD

Stepwise regression analysis for effects of FH on AUC indicated better model fit with the addition of callousness and unemotional main effects and with $\mathrm{ADHD} \times$ unemotional, $\mathrm{FH} \times$ callousness, $\mathrm{FH} \times$ unemotional, and $\mathrm{ADHD}$ $\times \mathrm{FH} \times$ unemotional interaction effects. This model showed no significant effects of $\operatorname{ADHD}\left(p=0.164, \eta_{\mathrm{p}}{ }^{2}=\right.$ $0.008), \mathrm{FH}\left(p=0.57, \eta_{\mathrm{p}}{ }^{2}=0.001\right)$, and ADHD $\times \mathrm{FH}$ effects on AUC ( $\left.p=0.073, \eta_{\mathrm{p}}{ }^{2}=0.013\right)$. Yet, we found a significant FH $\times$ callousness interaction effect $\left(p=0.024, \eta_{\mathrm{p}}{ }^{2}=\right.$ 0.019 ). Post hoc analysis suggested a trend for a negative association between scores in callousness scale and AUC in the $\mathrm{FH}+$ groups $\left(p=0.066, \eta_{\mathrm{p}}{ }^{2}=0.026\right.$; Fig. 3$)$.

Moreover, there was a significant 3-way interaction for $\mathrm{ADHD} \times \mathrm{FH} \times$ unemotional scores on $\mathrm{AUC}(p=0.039$, $\left.\eta_{\mathrm{p}}{ }^{2}=0.016\right)$. Post hoc analysis showed a significant ADHD $\times$ unemotional interaction effect in the $\mathrm{FH}-$ groups $(p=$ $\left.0.007, \eta_{\mathrm{p}}{ }^{2}=0.056\right)$ and a significant $\mathrm{FH} \times$ unemotional interaction effect in the ADHD groups $\left(p=0.003, \eta_{\mathrm{p}}{ }^{2}=\right.$ 0.062). In ADHD FH-, scores in the unemotional scale were negatively associated with AUC $\left(p=0.007, \eta_{\mathrm{p}}{ }^{2}=\right.$ $0.121)$. In contrast, the ADHD FH+ and the control FHgroups showed marginally significant $\left(p=0.049, \eta_{\mathrm{p}}{ }^{2}=\right.$ 
Fig. 2. Subjective values for each delay during delay discounting (DD) task. ADHDonly, ADHD without substance misuse (brown solid line); ADHD + SM, ADHD with substance misuse (SM) (orange dashed line), and controls (black dotted line); error bars, standard error of the mean.

Fig. 3. Association between the area under the curve (AUC) and the callousness scale of the Inventory of Callous-Unemotional Traits (ICU) in participants with negative family history of SUD (FH-; black squares and dashed regression line) and positive family history of SUD (FH+; blue circles and solid regression line); AUCs are before transformation to normality.
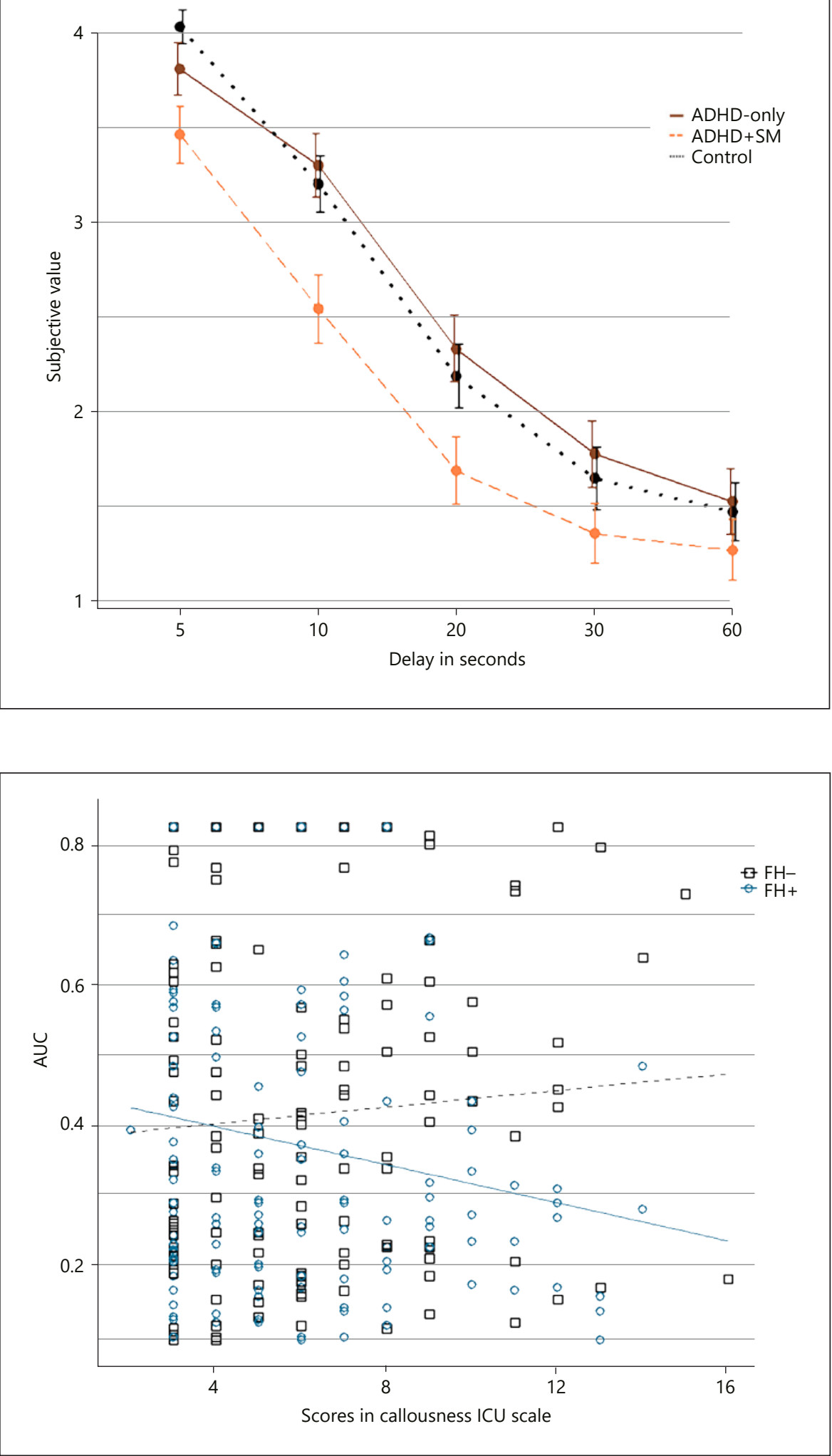
0.048 ) and non-significant $\left(p=0.133, \eta_{\mathrm{p}}^{2}=0.034\right)$ positive association between scores on the unemotional scale and AUC, respectively (online suppl. Fig. 3). There was also a significant site effect $\left(p=0.021, \eta_{\mathrm{p}}{ }^{2}=0.021\right)$.

\section{Effects of SM}

Stepwise regression for effects of SM suggested better model fit for the initial model without caring, unemotional, and callousness main or interaction effects.

\section{Confounder Analysis}

Results did not deviate significantly after addition of IQ and ADHD medication. These can be found in online suppl. material 1.

\section{Discussion/Conclusion}

The present study provides new insights into DD in adolescents and young adults with ADHD and the potential effects of SM and of FH of SUD on DD in this population. First, we investigated the effects of $\mathrm{FH}$ in ADHD and healthy controls (all without SM). There were no main effects of FH or ADHD on DD. Second, we examined the effects of SM in an FH-matched ADHD sample with and without SM. We found steeper DD for ADHD $+\mathrm{SM}$ than for ADHD-only patients. Exploring the effects of co-occurring CU traits, we found steeper DD in FH+ ADHD and control participants with higher callousness scores. We also observed steeper DD in ADHD FH- participants with higher unemotional scores, as opposed to steeper DD in ADHD FH+ and control FH- participants with lower unemotional scores.

Results do not support our hypothesis for steeper DD as part of familial risk for SUD. Lack of differences between $\mathrm{FH}+$ and $\mathrm{FH}$ - individuals is in line with some previous studies in the general population $[46,47]$ but contrasts with other studies that showed steeper DD in FH+ individuals $[16,17]$. High heterogeneity in DD performance within $\mathrm{FH}+$ populations might explain these results. DD might not be associated with FH per se but instead with a set of (endo)phenotypic features that are often present in $\mathrm{FH}+$ individuals, for instance, psychopathic traits. This might have contributed to inconsistent results in the literature $[16,17,46,47]$.

The results do support our hypothesis that SM is associated with more DD in ADHD patients. This is in line with a previous study that showed greater DD in ADHD patients with versus without cocaine dependence [18]. In the present study, we additionally accounted for potential effects of $\mathrm{FH}$, using groups that were matched for $\mathrm{FH}$. Our findings thus indicate greater DD as a consequence of SM in the ADHD patients. Future studies should examine neurobiological underpinnings of this effect (e.g., associated with substance use related alterations within corticostriatal reward network) and the effect of longterm abstinence [48].

Substance use habits are thought to reflect an impulsive choice between short-term reinforcement resulting from substance use and persistent reinforcement associated with abstinence [49]. Interestingly, DD was found to predict relapse in adolescent marijuana abusers [49]. DD might thus be a valuable marker for treatment outcome in ADHD-SUD patients. Notably, a previous study examined the relationship between DD and outcome of voucher-based contingency management therapy. Steeper DD was associated with shorter abstinence periods for lowbut not for high-magnitude vouchers [50]. DD might thus also be of interest as a marker to personalize treatment in SUD patients with ADHD, for instance, concerning the magnitude of vouchers in contingency management therapy.

Against our expectation, we did not observe a difference in DD between ADHD without SM and healthy controls. This is in contrast with previous meta-analyses of Patros et al. [9] and Jackson and MacKillop [10]. Yet, our findings are compatible with those of Crunelle et al. [18], which accounted for comorbid cocaine dependence and reported similar performance between the purely ADHD group and healthy controls. Undetected SM in a substantial number of adolescent and adult patients with ADHD might have contributed to findings in the literature. However, it is important to note that Patros et al. [9] included a number of studies in young children with ADHD. It is unlikely that findings in these studies were influenced by substance use effects (i.e., resulting from prior SM). Notably, some studies in younger ADHD patients reported positive effects of age, suggesting that adolescents with ADHD show less impulsive choice than children with ADHD [51]. Therefore, discrepancy between results in younger ADHD patients and ours in adolescent/adult ADHD-only patients might reflect differences in impulsive choice in this patient group across developmental stages. Moreover, in contrast with these studies in younger participants, we found negative effects of age, although these effects were small. It is possible that the relatively small reward magnitudes that could be gained (during an actual DD task) may not have been worth waiting for the older participants. 
Exploring the effect of CU traits, we found steeper DD for higher callousness scores in the FH+ groups. This suggests that the trend for overall steeper DD in the FH+ groups was mainly driven by an $\mathrm{FH}+$ subgroup with high callousness scores. High callousness scores are believed to reflect lack of empathy and guilt or remorse for misdeeds toward others [52]. Literature shows a positive association between these scores and aggressive or antisocial behavior measures [52]. Our results are in line with previous literature showing that steeper DD in an $\mathrm{FH}+$ group was mediated by high antisocial traits [22]. Notably, in our study, this relationship was not found for $\mathrm{FH}$ - groups, implying a unique role of callous personality traits in $\mathrm{FH}+$ individuals. The findings thus suggest that steeper DD might be part of familial effects in an $\mathrm{FH}+$ subgroup that is also characterized by increased callous personality traits.

We also observed steeper DD for higher unemotional scores in ADHD with $\mathrm{FH}-$, as opposed to the other groups. Increased scores in the unemotional scale are thought to reflect deficient emotional affect and thus lack of emotional expression [52]. Literature shows that this scale correlates to a lesser extent with the other ICU scales [53] and measures part of CU traits that are not related to antisocial and aggressive behaviors [54]. Importantly, self-reported sensation seeking was previously associated positively with callousness but negatively with unemotional scores [52]. Different aspects of CU traits seem to have different roles in DD performance in ADHD FH+ versus ADHD FH-. This might suggest distinct underlying processes leading to similar DD performance in different ADHD subgroups.

It is still unclear whether $\mathrm{CD}$ has a mediating role in the causal pathway from ADHD to SUD. Our results are in line with a pathway from ADHD to SM through CU traits that, at cognitive level, might be mediated by DD. Therefore, impulsive choice might represent an endophenotypic mechanism associated transdiagnostically with antisocial phenotypes, linking ADHD and SUD.

Our study has both strengths and limitations. The main strength lies in the design of the study that allowed us to disentangle between FH effects and effects of SM on $\mathrm{DD}$, by using an $\mathrm{FH}+$ sample without substance misuse (for effects of FH of SUD analysis) and an FH-matched sample with and without SM (for effects of SM analysis). Moreover, our groups did not differ in other potential cofounding variables (i.e., age, site for all groups, gender, and ADHD medication for ADHD groups). Yet, in the SM analysis, matching all groups with $\mathrm{FH}$ and only the ADHD groups with gender, based on the characteristics of ADHD + SM (i.e., the smallest group), resulted in FH and gender imbalance within groups. Data did not allow us to also match controls with gender, which resulted into a significant difference in gender ratio between the ADHD groups and controls. To avoid reporting gender instead of group differences, gender main and interactive effects were included in all analyses as covariates but were not significant. Another limitation lies in the instrument used to examine substance use in participants. This measured frequency of alcohol, drug, and nicotine use. This information was sufficient to define SM but not to consider criteria for SUD. Future studies should investigate the role of DD in ADHD and SUD comorbid groups. Moreover, the age range in the present study was not optimal for defining SUD. Participants might have been too young (average age 17-18 years) to develop SUD. Yet, early SM is regarded as a precursor for future SUD development [13], which underscores the relevance of our findings. Another limitation is the absence of formal SUD diagnosis in parents. Yet, the instruments used to screen for SUD in parents (i.e., AUDIT, DAST, FTND, and TLFB) were previously found to be reliable and valid $[28,29,31,32$, 55].

To conclude, we did not find main effects of FH on DD in ADHD and healthy control individuals. Yet, we found greater DD as a result of SM in ADHD patients. Moreover, high callous traits were associated with steeper discounting in ADHD FH+ and control FH+. Steeper DD might thus be part of familial trait effects in an FH+ subgroup with high CU traits. Overall, results suggest a pathway from $\mathrm{ADHD}$ to $\mathrm{SM}$ through $\mathrm{CU}$ traits that, at cognitive level, is mediated by DD. Efficacy of early interventions that target $\mathrm{CU}$ traits and impulsive choice in this population needs future investigation.

\section{Acknowledgements}

This work was supported by VENI Grant 916.15.101 (to A.F.A.S.) from the Netherlands Organisation for Scientific Research (NWO) and grants from the Radboud University Nijmegen Medical Center. The NeuroIMAGE project was supported by NIH Grant R01MH62873 (to Stephen V. Faraone), NWO Large Investment Grant 1750102007010 and ZonMw Grant 60-6060097-193 (to J.K.B.), and grants from the Radboud University Nijmegen Medical Center, University Medical Center Groningen, Accare, and VU University Amsterdam, and an unrestricted grant from Shire Pharmaceuticals (to Stephen V. Faraone). The work was further supported by the Horizon 2020 programme of the European Union (Grant No. 667302 for the Comorbid Conditions of Attention-deficit/Hyperactivity Disorder [CoCA] consortium). 


\section{Statement of Ethics}

The sample of the present study consisted of participants of the NeuroIMAGE project. This was approved by the Regional Ethics Committee (Centrale Commissie Mensgebonden Onderzoek: CMO Regio Arnhem Nijmegen; 2008/163; ABR: NL23894.091.08) and the Medical Ethics Committee of the VU University Medical Center. Informed consent was obtained for every participant. For participants younger than 12 years, parents gave consent, while for participants aged 12-18 years, both participants and their parents gave consent. More detailed information about this procedure is included in the main design paper of NeuroIMAGE [24].

\section{Conflict of Interest Statement}

J.K.B. has been a consultant to/member of advisory board of, and/or speaker for Janssen Cilag BV, Eli Lilly, Roche, Medice, Takeda/Shire, Novartis, and Servier. He is not an employee or a stock shareholder of any of these companies. He has no other financial or material support, including expert testimony, patents, and royalties. The other authors declare no biomedical financial interests or potential conflicts of interest.

\section{Funding Sources}

Information related to funding is included in the Acknowledgements section.

\section{Author Contributions}

M.P. has contributed to the project design, data preprocessing and analysis, interpretation of the results, and writing of the manuscript. D.R. has contributed to the project design, data acquisition and analysis, interpretation of the results, and writing and revision of the manuscript. A.H.S. has contributed to the project design, interpretation of the results, and revision of the manuscript. A.P.J.S. has contributed to data preprocessing and revision of the manuscript. J.K.B. has contributed to the project design, interpretation of the results, and revision of the manuscript. A.F.A.S. has contributed to the conception and design of the project, data analysis, interpretation of the results, and writing and revision of the manuscript. All authors have approved the publication of the manuscript.

\section{References}

1 Thomas R, Sanders S, Doust J, Beller E, Glasziou P. Prevalence of attention-deficit/hyperactivity disorder: a systematic review and metaanalysis. Pediatrics. 2015;135(4):e994-1001.

2 Faraone SV, Biederman J, Mick E. The agedependent decline of attention deficit hyperactivity disorder: a meta-analysis of follow-up studies. Psychol Med. 2006;36(2):159-65.

3 Biederman J, Wilens T, Mick E, Milberger S, Spencer TJ, Faraone SV. Psychoactive substance use disorders in adults with attention deficit hyperactivity disorder (ADHD): effects of ADHD and psychiatric comorbidity. Am J Psychiatry. 1995;152:1652-8.

4 Sizoo B, van den Brink W, Koeter M, Gorissen van Eenige $M$, van Wijngaarden-Cremers $P$, van der Gaag RJ. Treatment seeking adults with autism or ADHD and co-morbid substance use disorder: prevalence, risk factors and functional disability. Drug Alcohol Depend. 2010;107(1):44-50.

5 Wittchen HU, Jacobi F, Rehm J, Gustavsson A, Svensson M, Jönsson B, et al. The size and burden of mental disorders and other disorders of the brain in Europe 2010. Eur Neuropsychopharmacol. 2011;21(9):655-79.

6 Buitelaar JK, Kan CC, Asherson PJ. ADHD in adults. Ugeskrift for laeger. 2008;170:3395-9.

7 Wilens TE. Impact of ADHD and its treatment on substance abuse in adults. J Clin Psychiatry. 2004;65(Suppl 3):38-45.

8 Castells X, Ramos-Quiroga JA, Rigau D, Bosch R, Nogueira M, Vidal X, et al. Efficacy of methylphenidate for adults with attentiondeficit hyperactivity disorder: a meta-regression analysis. CNS Drugs. 2011;25(2):157-69.
9 Patros CHG, Alderson RM, Kasper LJ, Tarle SJ, Lea SE, Hudec KL. Choice-impulsivity in children and adolescents with attention-deficit/hyperactivity disorder (ADHD): a metaanalytic review. Clin Psychol Rev. 2016;43: 162-74. Available from:

10 Jackson JNS, MacKillop J. Attention-deficit/ hyperactivity disorder and monetary delay discounting: a meta-analysis of case-control studies. Biol Psychiatry Cogn Neurosci Neuroimaging. $2016 \mathrm{Jul} ; 1(4): 316-25$.

11 MacKillop J, Amlung MT, Few LR, Ray LA, Sweet LH, Munafò MR. Delayed reward discounting and addictive behavior: a metaanalysis. Psychopharmacology. 2011;216(3): 305-21.

12 Amlung M, Vedelago L, Acker J, Balodis I, Mackillop J. Steep delay discounting and addictive behavior: a meta-analysis of continuous associations. Addiction. 2017;112:51-62.

13 Adisetiyo V, Gray KM. Neuroimaging the neural correlates of increased risk for substance use disorders in attention-deficit/hyperactivity disorder: a systematic review. Am J Addict. 2017;26(2):99-111.

14 Anokhin AP, Golosheykin S, Grant JD, Heath AC. Heritability of delay discounting in adolescence: a longitudinal twin study. Behav Genet. 2011;41(2):175-83.

15 Setlow B, Mendez IA, Mitchell MR, Simon NW. Effects of chronic administration of drugs of abuse on impulsive choice (delay discounting) in animal models. Behav Pharmacol. 2009;20(5-6):380-9.

16 Dougherty DM, Charles NE, Mathias CW, Ryan SR, Olvera RL, Liang Y, et al. Delay dis- counting differentiates pre-adolescents at high and low risk for substance use disorders based on family history. Drug Alcohol Depend. 2014;143(1):105-11.

17 Dougherty DM, Lake SL, Mathias CW, Ryan SR, Bray BC, Charles NE, et al. Behavioral impulsivity and risk-taking trajectories across early adolescence in youths with and without family histories of alcohol and other. Drug Use Disorders. 2015;39(8):1501-9.

18 Crunelle CL, Veltman DJ, Van Emmerik-van Oortmerssen K, Booij J, Van den Brink W. Impulsivity in adult $\mathrm{ADHD}$ patients with and without cocaine dependence. Drug Alcohol Depend. 2013;129(1-2):18-24.

19 Edwards AC, Kendler KS. Twin study of the relationship between adolescent attentiondeficit/hyperactivity disorder and adult alcohol dependence. J Stud Alcohol Drugs. 2012; 73(2):185-94.

20 Blair RJR. The neurobiology of psychopathic traits in youths. Nat Rev Neurosci. 2013; 14(11):786-99.

21 Frick, PJ, Moffitt TE. A proposal to the DSM$\mathrm{V}$ childhood disorders and the ADHD and disruptive behavior disorders work groups to include a specifier to the diagnosis of conduct disorder based on the presence of callous-unemotional traits. Washington, DC: Am Psychiatr Assoc; 2010;1-36.

22 Acheson A, Vincent AS, Sorocco KH, Lovallo WR. Greater discounting of delayed rewards in young adults with family histories of alcohol and drug use disorders: studies from the Oklahoma family health patterns project. $\mathrm{Al}-$ cohol Clin Exp Res. 2011;35(9):1607-13. 
23 Petry NM. Discounting of delayed rewards in substance abusers: Relationship to antisocial personality disorder. Psychopharmacology. 2002;162(4):425-32.

24 von Rhein D, Mennes M, van Ewijk H, Groenman AP, Zwiers MP, Oosterlaan J, et al. The NeuroIMAGE study: a prospective phenotypic, cognitive, genetic and MRI study in children with attention-deficit/hyperactivity disorder. Design and descriptives. Eur Child Adolesc Psychiatry. 2014;24:265-81.

25 Kaufman J, Birmaher B, Brent D, Rao UMA, Flynn C, et al. Schedule for affective disorders and schizophrenia for school-age childrenpresent and lifetime version (K-SADS-PL): initial reliability and validity data. J Am Acad Child Adolesc Psychiatry. 1997;36(7):980-8.

26 Conners CK, Sitarenios G, Parker JDA, Epstein JN. Revision and restandardization of the Conners teacher rating scale (CTRS-R): factor structure, reliability, and criterion validity. J Abnorm Child Psychol. 1998;26(4): 279-91.

27 Conners, CK, Erhardt, D, Epstein, JN, Parker, JDA, Sitarenios, G, Sparrow E. Self-ratings of ADHD symptoms in adults I: factor structure and normative data. J Atten Disord. 1999; 3(3):141-51.

28 Saunders JB, Aasland OG, Babor TF, De La Fuente JR, Grant M. Development of the alcohol use disorders identification test (AUDIT): WHO collaborative project on early detection of persons with harmful alcohol consumption-II. Addiction. 1993 Jun;88(6): 791-804.

29 Gavin DR, Ross HE, Skinner HA. Diagnostic validity of the DAST in the assessment of DSM-III drug disorders. Br J Addict. 1989;84: 301-7.

30 Heatherton TF, Kozlowski LT, Frecker RC, Fagerstrom K-O. The Fagerström test for nicotine dependence: a revision of the Fagerstrom Tolerance Questionnaire. Br J Addict. 2018;86(9):1119-27.

31 Sobell LC, Brown J, Leo GI, Sobell MB. The reliability of the Alcohol Timeline Followback when administered by telephone and by computer. Drug Alcohol Depend. 1996;42(1):4954.

32 Brown RA, Burgess ES, Sales SD, Whiteley JA, Evans DM, Miller IW. Reliability and validity of a smoking timeline follow-back interview. Psychol Addict Behav. 1998;12(2):101-12.

33 Hagman BT. Performance of the AUDIT in detecting DSM-5 alcohol use disorders in College Students in College Students. Subst Use Misuse. 2016;51(11):1521-8.
34 NIAAA Alcohol \& Your Health website. Drinking levels defined [Internet]. [cited 2017 Jul 14]. Available from: https://www.niaaa. nih.gov/alcohol-health/overview-alcoholconsumption/moderate-binge-drinking.

35 National Institute on Drug Abuse (NIDA) Question: Your score was: Your level of dependence on nicotine is: [Internet]. [cited 2019 Jul 13]. Available from: https://cde.drugabuse.gov/instrument/d7c0b0f5-b865e4de-e040-bb89ad43202b/module/f7cc1db9-2f13--70d5-e040-bb89ad4345a3/question/ f7cc1db9--2f15--70d5-e040-bb89ad4345a3.

36 Loeber R, Wung P, Keenan K, Giroux B, Stouthamer-Loeber M, Van Kammen WB, et al. Developmental pathways in disruptive child behavior. Dev Psychopathol. 1993;5(12):103-33.

37 Elliott, DS, Huizinga, D, Ageton SS. Explaining delinquency and drugs use. Beverly Hills, CA: Sage; 1985

38 Schippers GM, Broekman TG, Buchholz A, Koeter MWJ, Van Den Brink W. Measurements in the Addictions for Triage and Evaluation (MATE): an instrument based on the World Health Organization family of international classifications. Addiction. 2010;105(5): 862-71.

39 RStudio Team. RStudio. Integrated Development for R. RStudio, Inc., Boston, MA. Available from: http://www.rstudio.com/.

40 Ho DE, Imai K, King G, Stuart EA. MatchIt: nonparametric preprocessing for parametric causal inference. J Stat Softw. 2011;42(8). Available from: http://www.jstatsoft.org/v42/ i08/.http://dx.doi.org/10.18637/jss.v042.i08

41 Kimonis ER, Frick PJ, Skeem JL, Marsee MA, Cruise K, Munoz LC, et al. Assessing callousunemotional traits in adolescent offenders: validation of the inventory of callous-unemotional traits. Int J Law Psychiatry. 2008;31(3): 241-52.

42 Byrd, AL, Kahn, RE, Pardini DA. A validation of the inventory of callous-unemotional traits in a community sample of young adult males. J Psychopathol Behav Assess. 2014;35(1):126.

43 Scheres A, Tontsch C, Thoeny AL, Sumiya M. Temporal reward discounting in children, adolescents, and emerging adults during an experiential task. Front Psychol. 2014;5(Jul):17.

44 Mies GW, de Water E, Wiersema JR, Scheres A. Delay discounting of monetary gains and losses in adolescents with ADHD: contribution of delay aversion to choice. Child Neuropsychol. 2019;25(4):528-47.
45 Mies GW, Ma I, de Water E, Buitelaar JK, Scheres A. Waiting and working for rewards: attention-deficit/hyperactivity disorder is associated with steeper delay discounting linked to amygdala activation, but not with steeper effort discounting. Cortex. 2018;106:164-73.

46 Petry NM, Kirby KN, Kranzler HR. Effects of gender and family history of alcohol dependence on a behavioral task of impulsivity in healthy subjects. J Stud Alcohol. 2002;63(1): 83-90.

47 Herting MM, Schwartz D, Mitchell SH, Nagel BJ. Delay discounting behavior and white matter microstructure abnormalities in youth with a family history of alcoholism. Alcohol Clin Exp Res. 2010;34(9):1590-602.

48 Schulte MHJ, Cousijn J, den Uyl TE, Goudriaan AE, van den Brink W, Veltman DJ, et al. Recovery of neurocognitive functions following sustained abstinence after substance dependence and implications for treatment. Clin Psychol Rev. 2014;34(7):531-50.

49 Stanger C, Ryan SR, Landes RD, Jones BA, Bickel WK. Delay discounting predicts adolescent substance abuse treatment outcome. Exp Clin Psychopharmacol. 2014;20(3):20512.

50 Washio Y, Higgins ST, Heil SH, McKerchar TL, Badger GJ, Skelly JM, et al. Delay discounting is associated with treatment response among cocaine-dependent outpatients. Exp Clin Psychopharmacol. 2011 Jun; 19(3):243-8.

51 Scheres A, Dijkstra M, Ainslie E, Balkan J, Reynolds B, Sonuga-Barke E, et al. Temporal and probabilistic discounting of rewards in children and adolescents: effects of age and ADHD symptoms. Neuropsychologia. 2006; 44(11):2092-103.

52 Essau CA, Sasagawa S, Frick PJ. Callous-unemotional traits in a community sample of adolescents. Assessment. 2006;13(4):454-69.

53 Berg JM, Lilienfeld SO, Reddy SD, Latzman $\mathrm{RD}$, Roose A, Craighead LW, et al. The inventory of callous and unemotional traits: a construct-validational analysis in an at-risk sample. Assessment. 2013;20(5):532-44.

54 Cardinale EM, Marsh AA. The reliability and validity of the inventory of callous unemotional traits: a meta-analytic review. Assessment. 2020;27(1):57-71.

55 Meneses-Gaya ICde, Zuardi AW, Loureiro SR, Crippa JAde S. Psychometric properties of the Fagerström test for nicotine dependence. J Bras Pneumol. 2009 Jan;35(1):7382. Available from: http://www.scielo.br/ scielo.php?script $=$ sci_arttext $\&$ pid $=$ S1806$37132009000100011 \& \operatorname{lng}=$ en\&tlng $=$ en . 